\title{
Can routinely recorded reproductive events be used as indicators of disease emergence in dairy cattle? An evaluation of 5 indicators during the emergence of bluetongue virus in France in 2007 and 2008
}

\author{
Alexis Marceau, ${ }^{*} \dagger \ddagger$ Aurélien Madouasse, ${ }^{\star} † \ddagger$ Anne Lehébel, ${ }^{*} † \ddagger$ Gerdien van Schaik,§ Anouk Veldhuis,§ \\ Yves Van der Stede,\#IIT and Christine Fourichon* ${ }^{*} \ddagger^{1}$ \\ ${ }^{*}$ Oniris, UMR1300 Biologie, Epidémiologie et Analyse de Risque en Santé Animale, La Chantrerie, CS 40706, F-44307 Nantes, France \\ †INRA, UMR1300, F-44307 Nantes, France \\ ‡Université Nantes (LUNAM), Angers, Le Mans, F-44200, Nantes, France \\ $\S$ GD Animal Health, Epidemiology Group, PO Box 9, 7400 AA Deventer, the Netherlands \\ \#Coordination Veterinary Diagnostics-Epidemiology and Risk Assessment (CODA-CERVA), Groeselenberg 99, 1180 Brussels, Belgium \\ IILaboratory of Veterinary Immunology, Faculty of Veterinary Medicine, Salisburylaan 133, 9820 Merelbeke, Belgium \\ ILaboratory of Veterinary Immunology, Ghent University, Faculty of Veterinary Medicine, Salisburylaan 133, 9820 Merelbeke, Belgium
}

\section{ABSTRACT}

In response to increasing risks of emerging infectious diseases, syndromic surveillance can be a suitable approach to detect outbreaks of such diseases across a large territory in an early phase. To implement a syndromic surveillance system, the primary challenge is to find appropriate health-related data. The objective of this study was to evaluate whether routinely collected dates of reproductive events in dairy cattle could be used to build indicators of health anomalies for syndromic surveillance. The evaluation was performed on data collected in France between 2003 and 2009. First, a set of 5 indicators was proposed to assess several types of reproductive disorders. For each indicator, the demographic coverage over the total number of cattle at risk was analyzed in time and space. Second, the ability to detect an emerging disease in an early phase was retrospectively evaluated during epidemics of bluetongue serotypes 1 and 8 (BTV-1, BTV-8) in France in 2007 and 2008. Reproductive indicators were analyzed weekly during these epidemics for each indicator in each infected French district (16 in 2007 and 50 in 2008 out of 94 districts). The indicators were able to detect the BTV epidemics despite their low demographic coverage on a weekly basis relatively to total number of cattle (median $=1.21 \%$; range $=0-11.7 \%$ ). Four indicators related to abortions, late embryonic death, and short gestations were abnormally elevated during both BTV epidemics. Median times to abnormal elevations in these indicators were 20 to $71 \mathrm{~d}$ after the first notification of clinical signs of BTV by veterinarians. These results demonstrate that reproduction data can

Received August 7, 2013.

Accepted May 5, 2014

${ }^{1}$ Corresponding author: christine.fourichon@oniris-nantes.fr be used as indicators of disease emergences, whereas in the specific case of these BTV epidemics, detection via these indicators was later than clinical detection by veterinarians. The emergence of bluetongue in 2007 in France was associated with gestations that were a few days shorter than expected. A short gestation indicator underwent high elevations relative to prior random fluctuations and was the earliest (out of the 4 indicators) to show abnormal elevations, making it possible to detect this emergence.

Key words: syndromic surveillance, reproductive indicators, bluetongue epidemic, disease emergence

\section{INTRODUCTION}

The global increase in emerging infectious diseases requires that public and animal health institutes develop surveillance programs that are capable of detecting emergence of a disease as fast as possible (Jones et al., 2008). For cattle, several recent disease emergences have been described in Europe. Six exotic bluetongue virus (BTV) serotypes have been detected since 1998. One serotype, BTV-8, caused a major epidemic from 2006 to 2008 in Northern Europe, with important health and economic losses (Hateley, 2009; Wilson and Mellor, 2009). During fall 2011, an unknown virus named Schmallenberg emerged in Northern Europe (Hoffmann et al., 2012). Although the exact routes of introduction of these emerging diseases are difficult to trace, global warming and increasing international trade and travel increase the incidence of such epidemics (Mintiens et al., 2008; Purse et al., 2008). In this context, commonly implemented diagnostic-based active surveillance is not sufficient because it is limited to known diseases that could emerge or re-emerge (e.g., brucellosis and tuberculosis). Therefore, parallel nonspecific surveillance systems have to be developed for unexpected disease 
outbreaks such as the recent BTV and Schmallenberg virus emergences in Europe.

This syndromic surveillance approach is designed to early detect exceptional variations in nonspecific clinical signs or disorders caused by a disease in a large population. To implement such a system, the primary challenge is to find routinely collected data that can be used to indicate nonspecific signs (Shmueli and Burkom, 2010). The relevance of the data depends on their close association with clinical signs, the nonspecificity of signs, the demographic coverage, and the continuity of monitoring (Mandl et al., 2004; Buckeridge, 2007). For cattle, 4 data sources have already been evaluated for syndromic surveillance: mortality, notification of abortions, laboratory submissions, and milk production (Carpenter et al., 2007; Perrin et al., 2010; Brouwer et al., 2012; Madouasse et al., 2014). These were successfully used to retrospectively detect infectious diseases (BTV-8, brucellosis, or bovine viral diarrhea). However, timeliness of detection was not estimated and, for mortality in particular, it could be that "high mortality" is observed much later after the start of the epidemic, as was observed for humans during influenza epidemics (Choi and Thacker, 1981; Costagliola et al., 1991; Basu, 2009). Generally, to increase the range of diseases that can be detected, syndromic surveillance would benefit from using different data sources simultaneously to obtain complementary signs of health disorders.

Reproductive events such as AI and calving are routinely recorded for herd management purposes as well as for the genetic evaluation of sires. They have been successfully used in several studies to evaluate the effects of various diseases on reproductive performance in dairy cattle known to have been infected. For example, a lower rate of nonreturn to service was observed in dairy cattle infected with Mycobacterium avium ssp. paratuberculosis (Marcé et al., 2009), and lower rates of 56-d return to service were observed in dairy cattle infected with BTV-8 (Santman-Berends et al., 2010; Nusinovici et al., 2012b). However, these data have never been used for syndromic surveillance; that is, when the infection status is not known, but can be of interest because many diseases can have an effect on reproductive performance and gestation. The emergence in Europe of BTV-8, a virus that causes reproductive disorders (e.g., abortion and stillbirth; Elbers et al., 2008), provided the opportunity to assess the value of these indicators for syndromic surveillance.

The objective of this study was to evaluate the use of routinely collected reproduction data in dairy cattle to build indicators suitable for syndromic surveillance. First, the definition of 5 indicators of reproductive disorders was provided. Their demographic coverage in the French dairy cattle population was analyzed weekly and at the district level to assess their representativeness. Then, the ability of these indicators to detect reproductive disorders during the emergence of BTV in 2007 and 2008 in France was evaluated.

\section{MATERIALS AND METHODS}

\section{Description and Selection of Reproduction Data}

In French dairy cattle enrolled in the official milk recording scheme, AI and calving are extensively reported to the breeding organization by the farmers or inseminators for herd management purposes and genetic evaluation of sires. Farmers are required to report each calving (dead or alive) within $7 \mathrm{~d}$ with the date of the event, the identification number of the dam, the herd of birth, and the breed. In dairy cattle, most AI are performed by inseminators $(95.8 \%$ in 2012 ; Institut de l'élevage, 2012), who are required to report, within 2 wk, the date of the event as well as the identification of the animal and its herd. In addition, farmers must report dates of death or culling within $7 \mathrm{~d}$ to the national bovine identification database.

These data are centralized in a unique national database managed by Institut National de la Recherche Agronomique (INRA). The following variables were extracted from this database: dates of AI, dates of calving, dates of death/culling, identification numbers (ID) of animals, herd ID, and breeds. Only inseminated animals in herds enrolled in the official milk recording scheme were selected. To have a historic period before the 2007 BTV-8 epidemic and at least one full year after the end of the epidemic, data recorded from January 1, 2002, until December 31, 2009, were extracted. Breeds with several recorded calvings $>1,000$ calvings per year in at least one district were selected to AI on about 10 million animals located in about 100,000 herds over 8 yr.

\section{Description and Selection of BTV Notification Data}

The notification of a BTV infection in bovine herds (dairy and beef herds) was mandatory in France in 2007 and 2008. The recorded notifications consisted of those herds that had at least one animal diagnosed with BTV1 or BTV-8. In total, 8,603 and 18,259 bovine herds were notified in 2007 and 2008 respectively. Most of these notifications (93\%) corresponded to the BTV-8 epidemic, which began in July 2007 in northeastern France and reached most districts by the end of 2008 (79 out of 94 districts). The remainder of the notifications $(7 \%)$ corresponded to the BTV-1 epidemic, which spread only in southwestern France in 2008 (19 out of 94 districts). The following variables were available for each notified 
herd: herd ID, date of suspicion, date of confirmation, detection method (clinical signs or serological test), and BTV serotype. Only notifications following clinical suspicions were selected. A full description of the data set is available in Nusinovici et al. (2012a).

\section{Definitions of 5 Reproductive Indicators}

A set of 5 indicators was proposed to assess complementary reproductive disorders such as fertility disorders, embryonic deaths, abortions, and premature calving. A set of indicators (rather than a single indicator) was proposed because diseases do not induce these disorders at the same frequency in an infected population and consequently indicators are differently able to detect the epidemic. By using a set of indicators, the chance that one of them is related with a frequent disorder due to the disease increases and thus the chance to detect the disease increases. Three indicators were based on the interval between first AI after birth or calving and a second AI (i.e., return to service). Two indicators were based on the interval between the last recorded AI before calving (assumed to be the successful one) and calving. Time intervals were chosen according to their relation to particular reproductive disorders or health disturbances at the end of gestation (Figure 1). The 5 indicators were built separately for 2 parity groups, heifers (nulliparous at AI) and cows (parity $>0$ at AI), because large differences in frequencies of reproductive disorders in these populations were expected.

For the 3 indicators based on return to service (RTS), the following time intervals between first and second AI were chosen:

(1) 18 to $26 \mathrm{~d}$ (3-wk RTS), which could be associated with fertility disorders or early embryonic death (until 15-17 d after fecundation). The chosen bounds of the interval (18 and $26 \mathrm{~d}$ ) are an estimation of the normal range of the estrous cycle duration.

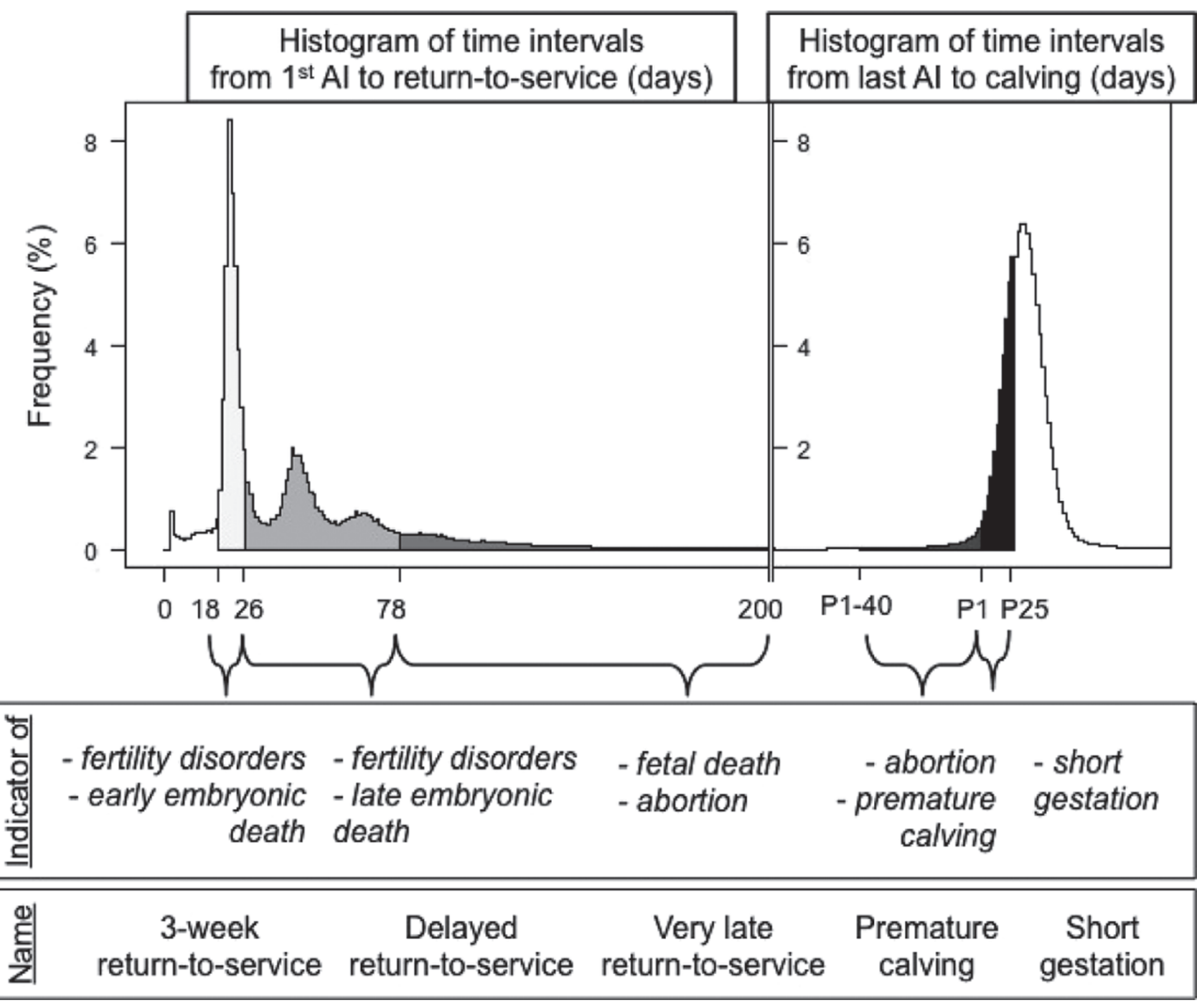

Figure 1. Definition of 5 indicators of reproductive disorders for syndromic surveillance based on routinely collected reproduction data in dairy cattle. Histograms were built using data recorded from 2003 to 2006 for cows inseminated in French dairy herds enrolled in the official milk recording scheme. Three indicators were defined as a function of time interval between first AI and return-to-service (left histogram) and 2 indicators were defined as a function of time interval between last AI and calving (right histogram). P1 and P25 correspond to the percentiles $1 \%$ and $25 \%$ of the Gaussian distribution of time interval between last AI and calving estimated for each breed and parity group. For all indicators, the name and the indicated reproductive disorders are given. 
(2) 27 to 77 d (delayed RTS), which could be associated with fertility disorders, late embryonic death (between 15 and 17 and $\sim 42$ d after the fecundation) or fetal death (between 42 and 260 $\mathrm{d}$ of gestation). The upper bound of the interval corresponds to 3 times the maximum duration of the cycle $(3 \times 26)$. This was chosen to account for the time needed for a new cycle to start, for the cow to come in heat and for the farmers to detect return to estrus.

(3) 78 to 200 d (very late RTS), which could be associated with fetal death or abortion. In the data, very few returns were observed after $200 \mathrm{~d}$ $(<2 \%$ for cows) and these events were not taken into account to reduce random fluctuation in the time series.

Only RTS after a first AI were used to ensure the reliability of these indicators. Indeed, most farmers re-inseminate their cows after a first return in heat, whereas the decision not to re-inseminate after a second and subsequent AI depends on the farmer, as well as on regional or country-specific constraints. For example, in France, it is common for farmers to pay a flat fee for the first 3 AI.

For the 2 indicators based on early calving, time intervals between the last AI and calving were chosen according to the percentiles of the Gaussian distribution of normal gestation lengths. The selected percentiles were 1 (P1) and 25 (P25). The 2 indicators were defined as follows:

(1) P1 - 40 d to P1 (premature calving), which could be associated with abortion or stillbirth (calves dead at birth or $48 \mathrm{~h}$ after birth). The number of recorded calvings below the lower bound was very low $(<1 \%)$ and they were excluded to reduce random fluctuation in the time series.
(2) P1 to P25 (short gestation), which could be associated with the occurrence of a health disorder (e.g., fever, which is the most frequent clinical sign observed in animals infected by BTV; Elbers et al., 2008) in the pregnant animal at the end of gestation. The assumption is that health disorders at this stage can induce the calving a few days earlier than expected.

To estimate P1 and P25, the Gaussian distribution of normal gestation lengths were estimated for each breed and parity group. Gaussian parameters were fitted on a sample of normal gestation length especially created to reduce the number of abnormal values due to abortions or errors in data recording. The sample included gestation lengths recorded over a period without any major epidemics (from 2003 to 2005), and gestation lengths $<260 \mathrm{~d}$ and $>320 \mathrm{~d}$ were removed. The Gaussian parameters were fitted on the sample by the least squares method and the estimates as well as P1 and P25 for all populations are given in Table 1.

\section{Time Series of Daily Rates of the Indicators}

The occurrences of each indicator were calculated as a rate related to populations at risk. These rates were calculated for each indicator and each parity group at the district level and on a weekly basis. The district level was chosen because this is the administrative unit commonly used for epidemiological surveillance in France and it allows a fine spatial resolution (median $\sim 6,000$ $\mathrm{km}^{2}$, range $\sim 100$ to $11,000 \mathrm{~km}^{2}$ ). Only 7 out of 94 districts had no AI in the selected data set. A weekly basis was chosen to reduce the very high random variability observed on a daily basis due to low size of population at risk. For each week, the daily observations within the week were aggregated to calculate the mean daily rate of occurrence observed that week, as follows:

Table 1. Estimated Gaussian distribution parameters (mean and SD) and percentiles 1 and 25\% (P1-P25) of time intervals between last AI and calving of parous cows and nulliparous heifers in dairy herds enrolled in the official milk recording scheme in France and that have calved between 2003 and 2006

\begin{tabular}{|c|c|c|c|c|c|c|c|c|}
\hline \multirow[b]{2}{*}{ Breed } & \multicolumn{4}{|c|}{ Cows (parity $>0$ at AI) } & \multicolumn{4}{|c|}{ Heifers (parity $=0$ at AI) } \\
\hline & $\begin{array}{c}\mathrm{N}^{1} \\
\left(\times 10^{3}\right)\end{array}$ & Mean (d) & $\mathrm{SD}(\mathrm{d})$ & P1-P25 (d) & $\begin{array}{c}\mathrm{N} \\
\left(\times 10^{3}\right)\end{array}$ & Mean (d) & $\mathrm{SD}(\mathrm{d})$ & $\mathrm{P} 1-\mathrm{P} 25$ (d) \\
\hline Holstein & 2,974 & 282 & 5 & $270-278$ & 1,471 & 280 & 5 & $268-277$ \\
\hline Montbéliarde & 668 & 287 & 5 & $274-283$ & 258 & 286 & 5 & $274-283$ \\
\hline Normande & 471 & 286 & 5 & $274-282$ & 227 & 285 & 5 & $273-282$ \\
\hline Crossbred & 57 & 285 & 6 & $271-281$ & 24 & 283 & 6 & $269-279$ \\
\hline Abondance & 34 & 288 & 6 & $275-284$ & 11 & 288 & 6 & $275-284$ \\
\hline Brune & 28 & 290 & 5 & $277-286$ & 11 & 289 & 5 & $276-285$ \\
\hline Simmental & 26 & 290 & 5 & $278-287$ & 10 & 289 & 5 & $276-285$ \\
\hline Saosnoise & 14 & 283 & 6 & $270-279$ & 6 & 281 & 5 & $269-278$ \\
\hline Tarentaise & 12 & 286 & 6 & $274-283$ & 4 & 286 & 5 & $273-282$ \\
\hline Pie rouge & 3 & 283 & 6 & $269-279$ & 1 & 281 & 6 & $267-277$ \\
\hline
\end{tabular}

${ }^{1} \mathrm{~N}=$ number of calvings used to estimate Gaussian parameters (in thousands). 


$$
p_{i, w}=\frac{\sum_{d=1}^{7} n_{i, d}}{\sum_{d=1}^{7} N_{i, d}},
$$

where $p_{i, w}$ was the mean daily rate of indicator $i$ on week $w, d$ was defined as the $7 \mathrm{~d}$ of the week, $n_{i, d}$ was the number of indicator events $i$ (RTS or early calving) that occurred on day $d$, and $N_{i, d}$ was the number of at-risk animals present on day $d$ for indicator $i$.

For a given day and indicator, the number of at-risk animals corresponded to the animals present that day (not dead or culled) that were inseminated last time in the indicator-specific time interval (e.g., for the indicator delayed RTS: inseminated for the last time between 27 and $77 \mathrm{~d}$ ago). A total of 870 time series of daily rates were built corresponding to 5 indicators in 2 parity groups in 87 districts. Each time series had a length of 365 wk starting on January 1, 2003 (Wednesday), and ending on December 29, 2009 (Tuesday).

\section{Expected Indicator Rates in Absence of an Epidemic}

For each time series, the expected baseline (i.e., expected mean) and the expected upper confidence limit in the absence of a major epidemic were modeled. The model of expected baseline was fitted on a training data set that corresponded to a reference period without any major epidemics (from 2003 to 2005; i.e., before the BTV-8 epidemic in northwestern Europe). Taking into consideration that the response variable was a rate and that seasonality was observed in all time series, the expected baseline was modeled using a logistic harmonic regression over time (binomial errors and logit link):

$\ln \left(\frac{p_{t}}{1-p_{t}}\right)=\mu+\sum_{n=1}^{3} \alpha_{n} \times \cos \left(\frac{2 \pi t n}{52}\right)+\beta_{n} \times \sin \left(\frac{2 \pi t n}{52}\right)$,

where $p_{t}$ was the mean daily rate of occurrence of a given indicator in week $t$. Time was expressed in number of weeks since January 1, 2003. The annual seasonal pattern of 52 wk was modeled by 3 harmonics, $n$, chosen according to the Akaike's information criterion (AIC) to best fit all observed patterns. A smaller number of harmonics led to poorer accuracy, whereas a larger number led to over-fitting. The parameters $\mu, \alpha_{n}$, and $\beta_{n}$ were estimated by maximum likelihood using the $\mathrm{R}$ glm function (R Core Team, 2012). Weekly number of events and weekly number of animal-days at risk were given as inputs in the optimization procedure.

Expected baselines were calculated for all the time series from 2006 to 2009 (this period includes the BTV epidemic) and these predictions were used to calculate the upper bounds of the expected confidence interval over the same period. For a given week and indicator, the upper bound of one-sided confidence interval was calculated by a normal approximation with a confidence level of $\alpha=0.025$ (Eq. [3]; $z^{(1-\alpha)}=1.96$ ). A low $\alpha$ for confidence level was chosen to reduce the number of type I error:

$$
U=\hat{p}+1.96 \sqrt{\frac{\hat{p}(1-\hat{p})}{N}},
$$

where $U$ was the upper bound, $\hat{p}$ was the predicted mean daily rate of a given indicator, and $N$ was the number of animal-days at risk for a given indicator in a given week.

To compare the amount of deviation between indicators time series with a highly different order of magnitude, a standardized estimation of the deviation was introduced. The standardization corresponded to the percentage of deviation $(\boldsymbol{D})$ from the predicted baseline $(\hat{p})$ associated with $U$ (Eq. [4]).

$$
D=\frac{(U-\hat{p})}{\hat{p}} \times 100 \text {. }
$$

\section{Evaluation of Indicators: Demographic Coverage and Elevations During the BTV Epidemic}

The first step of the evaluation consisted of analyzing the demographic coverage of each indicator and its variability on a weekly basis and at the district level in 2009 , the most recent year in the database. The demographic coverage for a given indicator on a given week corresponded to the number of animals that were able to produce the indicator event on at least $1 \mathrm{~d}$ within the week (pregnant cows or post-AI cows within the time intervals used to define indicators). It was expressed as the number of animals fulfilling the criteria to be included in the calculation of the indicator and also as a percentage relative to the total number of cattle present. The total number of cattle present in 2009 was stationary and assumed equal to the total number of cattle present on January 1, 2009, in all districts, according to the annual French census (Institut de l'élevage, 2010). This number ranged between 0 and 781,229 animals depending on district (median $=157,901$ animals) for a total of about 20 million cattle in France.

The second step of the evaluation consisted of analyzing anomalies in the indicator's time series during the BTV epidemics of 2007 and 2008. This analysis was realized during each epidemic period in each district when the cumulated prevalence was significant. During these periods, BTV was assumed to have spread 
in a significant proportion of the population, which is the required condition to detect a disease by syndromic surveillance. A significant prevalence was defined as a yearly cumulative between-herd prevalence $>5 \%$ with several exposed herds $>100$. The prevalence was calculated each year in each district as the number of notified dairy herds that were present in the database divided by the total number of dairy herds present in the database. This corresponds to a total of 66 epidemic periods distributed in 16 districts in 2007 and in 50 districts in 2008. Each epidemic period started with the week of first notification by a veterinarian in the associated district and ended 16 wk later. The corresponding duration of $17 \mathrm{wk}$ is a rough estimation of the BTV epidemic in 1 district. Over each epidemic period, 3 criteria were calculated to evaluate the indicators: (1) the total percentage of error, (2) the number of weeks with abnormal elevations, and (3) the time interval between first notification by a veterinarian and the first detected anomaly due to the BTV epidemic. The criteria are described below.

(1) The first criterion provided an estimation of the effect of BTV on indicators over the whole epidemic period. The total percentage of error was calculated by summing differences between expected and observed numbers of indicator events and dividing it by the sum of expected number of indicator events. The expected number of indicator events for a given week was calculated by multiplying the expected daily rate of an indicator by the number of animal-days at risk.

(2) The second criterion corresponded to the number of weeks when the observed indicator rate was higher than the expected upper bound (Eq. [4]). Outside the BTV epidemic period and given the confidence level of the upper bound $(\alpha=0.025)$, the expected number of weeks with abnormal elevations over a period of similar length was 0.4 wk $(=2.5 \% \times 17$ wk duration $)$.

(3) The third criterion provided an estimation of the timeliness of detection. A difficulty in accurately estimating timeliness is identifying the first abnormal elevation produced by the BTV epidemic but not an abnormal elevation due to random noise in time series. To attribute the first abnormal elevation due to the BTV epidemic, 2 criteria were applied. First, because the BTV epidemic was a persistent event, the first week with abnormal elevation had to be followed by at least 3 consecutive weeks with abnormal elevations. Second, the first week with abnormal elevation had to occur between 1 mo before the start of the epidemic period (defined by notifica- tion of clinical signs) and 1 mo before its end. Then, the number of days between the end of the week with the first elevation (first day of next week) and the day of first notification by a veterinarian were calculated for each epidemic period. Time intervals were calculated for 2 parity groups separately and then pooled together to describe their distribution.

\section{RESULTS}

\section{Demographic Coverage of the Indicators over Time and Space}

A sufficient number of at-risk animals was included in the population under study for 10 breeds (Table 1). The absolute demographic coverage of the indicators was highly variable depending on district, indicator, and week (0 to 56,150 animals), which was mainly due to differences in dairy herd density (e.g., very late RTS indicator in Figure 2). In several districts in southeastern and central France only a small number of animals were at risk. The reason for this is urbanization or specialization of territories in production systems other than dairy cattle. The largest demographic coverage was associated with parous cows and for the indicator "very late RTS" for which the at-risk period has the longest time interval (see Figure 3 for the overall demographic coverage per week over France). Moreover, each indicator underwent seasonal variations during the year. Relative to the total cattle population, demographic coverage per district and per week was low, with a median of $1.2 \%$ ( 0 to $11.7 \%$ ). Because the 5 indicators had different populations at risk, the demographic coverage of the 5 indicators together was higher than individual demographic coverage of each indicator, with a median of $6.3 \%$ (0 to $19.5 \%$ ).

\section{Reliability of Expected Daily Rates of Indicators in the Absence of an Epidemic}

Seasonal variations in each indicator's daily rate were well accounted for by the models (Figures 4 and 5), with the mean error of the models close to zero (mean $=0.9 \%$ with a standard deviation $=3 \%$ ) over all training periods. The Gaussian approximation of the upper bound defined to encompass $97.5 \%$ of observations was slightly underestimated as only $94.9 \%$ of observations were below the upper bounds over all training periods. The highest deviations $(D)$ between expected upper bounds and baseline were observed for indicators with the lowest rates of occurrence: on average $+118 \%$ ( 40 to $398 \%$ ) for premature calving (which is an indicator that is less probable) and $+49 \%$ (16 to $230 \%$ ) for 3 -wk RTS (which is the most probable indicator to occur). For 


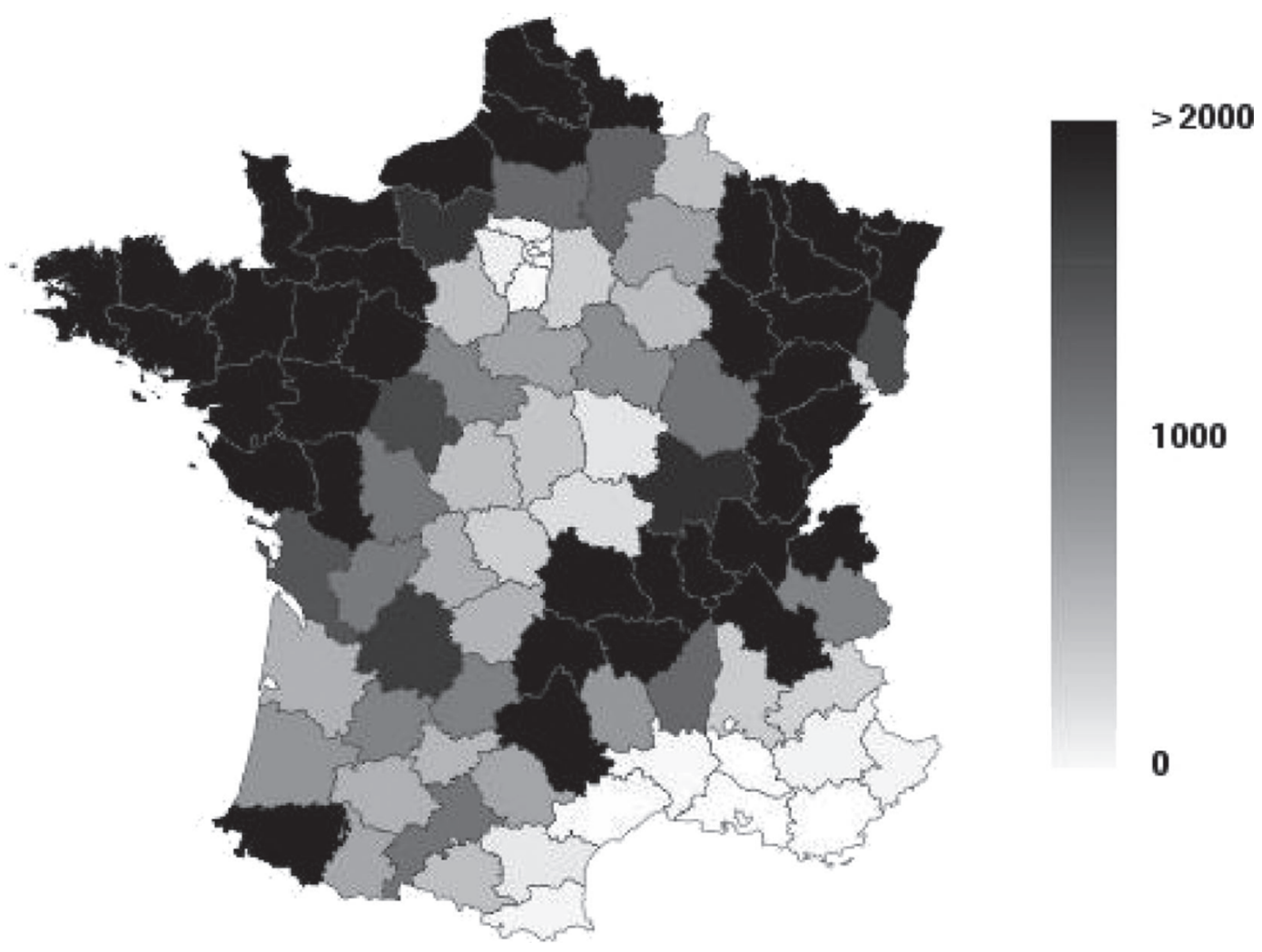

Figure 2. Number of parous dairy cows that were at risk at least 1 d during the first week of January 2009 in each of the 94 French districts for the indicator "very late return to service" (i.e., having had their first insemination after calving between 78 and $200 \mathrm{~d}$ before). This is a representative example of the variability of the absolute demographic coverage among districts for 1 indicator in 1 parity group over 1 wk. These numbers correspond to inseminated parous cows in dairy herds enrolled in the official milk recording scheme.

a given indicator, highest and lowest values of $D$ were observed during periods with the smallest and largest population at-risk, respectively.

\section{Evaluation of the Ability of the Indicators to Detect the BTV Epidemic Early}

On average, the total percentages of error during the BTV epidemic were positive for all indicators except for 3-wk RTS (Figure 6), which had errors close to zero. Highest total percentages of error were observed for very late RTS, premature calving, and short gestation in 2007, indicating the higher incidence of these events as a result of the BTV epidemic. These 3 indicators showed a decrease of around 11 percentage points from 2007 to 2008. The indicator delayed RTS had low positive errors, which decreased by 4 percentage points from 2007 to 2008. Overall, errors were similar between the cow and heifer populations.

The number of weeks with abnormal elevations over the epidemic periods was high for all indicators except for 3-wk RTS (Figure 7). The highest number of weeks with abnormal elevations corresponded to the indicator short gestation and for each population and year. For delayed RTS, very late RTS, premature calving, and short gestation, the number of weeks with abnormal elevations was high for cows in 2007. On average, the number of weeks with abnormal elevations was lower in 2008 than in 2007 (mean difference $=2 \mathrm{wk}$ ) and was lower for heifers than for cows (mean difference $=$ 2 wk). The number of weeks with abnormal elevations was related to the effect of BTV (estimated by the total percentage of error during the BTV epidemic) and to the weekly random variability of time series of indicator rates (indicated by the upper bound of the $97.5 \%$ confidence interval; Figure 8). The lower the random variability and the higher the effect of BTV, the greater the number of weeks with abnormal elevations.

Timeliness of indicators to detect BTV emergence was estimated using time series which had at least 4 consecutive weeks with abnormal elevations in either cow or heifer populations (Figure 9). The number of indicators per district with 4 consecutive weeks with abnormal elevations was lower in 2008 (median $=2$ indicators out of 10) than in 2007 (median $=4$ indicators out of 10 ). In $2007,0,25,47,34$, and $75 \%$ out of the 16 affected districts had 4 consecutive elevations for 3 -wk RTS, delayed RTS, very late RTS, premature calving, 


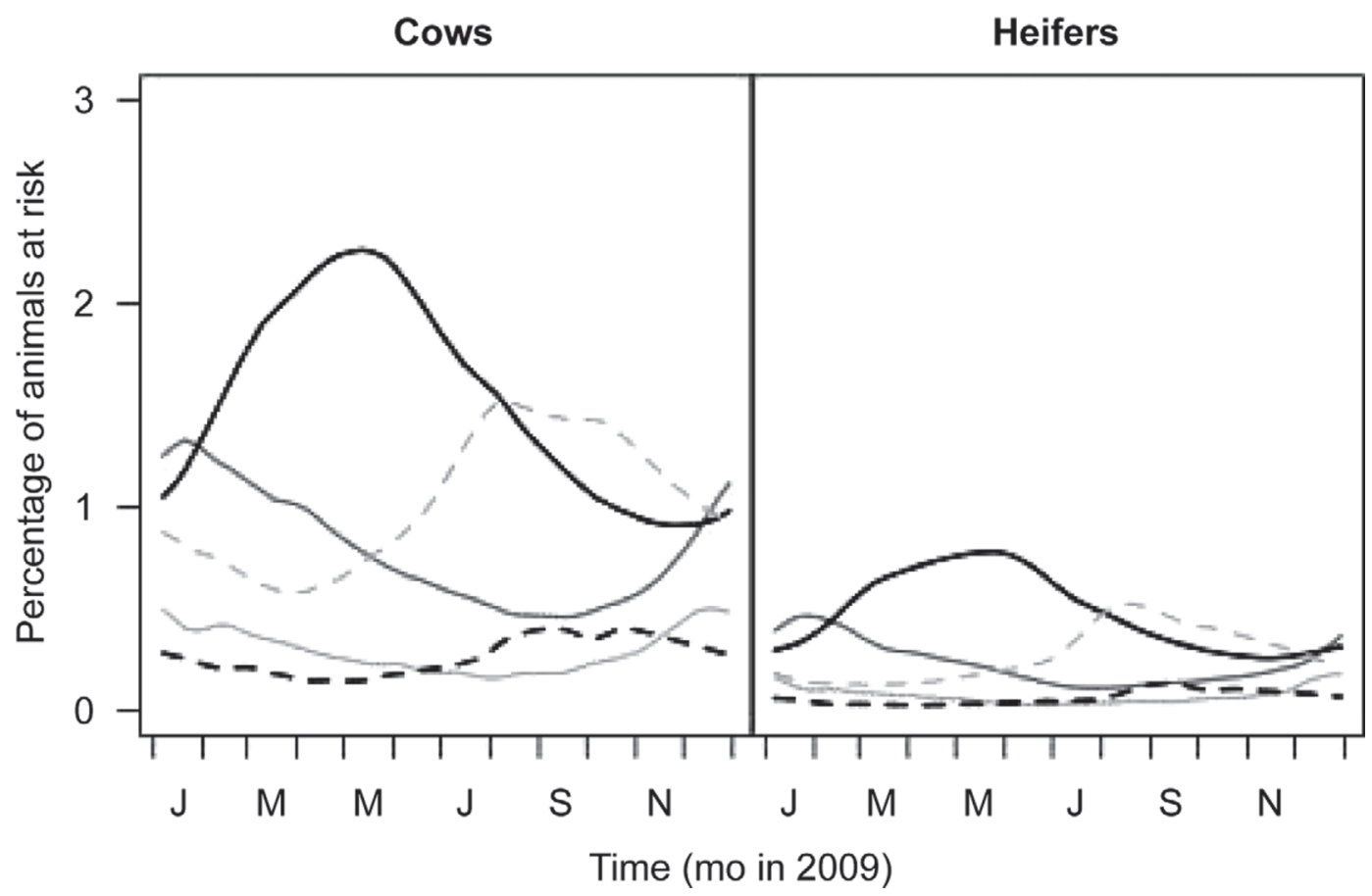

Figure 3. Temporal variability of the relative demographic coverage throughout France. Percentage of animals at risk at least $1 \mathrm{~d}$ over each week in 2009 all over France are plotted for the 5 indicators and 2 parity groups relative to the total number of cattle present on January $1,2009$. Animals at risk are dairy cows and heifers in herds enrolled in the official milk recording scheme. Three indicators based on return to service (RTS) are represented by solid lines: 3-wk RTS (light gray), delayed RTS (gray), and very late RTS (black). Two indicators based on gestation length are represented by dashed lines: premature calving (dashed light gray) and short gestation (dashed black).

and short gestation, respectively. In general, the detection of the BTV epidemic by indicators in each district occurred later than the first notifications by veterinarians based on clinical surveillance (Figure 10). This time delay was shortest when using the indicator "short gestation" and was much longer when using the indicator "very late RTS." The first notification of BTV-8 based on clinical signs on July 12, 2007, occurred $41 \mathrm{~d}$ earlier than the first detection by the short gestation indicator. This long delay can be explained by the very early first notification compared with the following notifications occurring $25 \mathrm{~d}$ later. When considering the second notification on August 6, 2007, the time delay is reduced to $16 \mathrm{~d}$.

\section{DISCUSSION}

\section{Reproduction Data Were Successfully Used to Detect the BTV Epidemic}

Five indicators constructed from routinely recorded reproduction events allowed detection of the emergence of BTV in France, despite a low demographic coverage (11.7\% at maximum). The set of indicators defined in the study was able to detect the BTV epidemic in most infected districts (with a prevalence $>5 \%$ and with several herds >100:): 57 out of 66 districts (16 districts in 2007 and 50 districts in 2008) had at least 4 consecutive weeks with abnormal elevations for at least one indicator during the BTV epidemic. Conversely to the common statement that indicators of syndromic surveillance require the highest demographic coverage possible, our study demonstrated the usefulness of indicators that were only available for a small part of the population. However, in infected districts with very low demographic coverage, detection was later and less frequent among indicators. Two factors explain this low demographic coverage: (1) only data collected in dairy herds enrolled in the official milk recording scheme were used, and (2) this number of animals was split over the 5 indicators. On January 1, 2009, inseminated dairy cows enrolled in a milk recording scheme in the median district represented only 11.7 and $4.3 \%$ of total cattle population for parous cows and nulliparous heifers, respectively (up to $34.3 \%$ for heifers and up to $14.8 \%$ for cows). Beef cattle represent $45 \%$ of total French cattle population (Institut de l'élevage, 2010). In districts with many beef cattle, the potential to increase demographic coverage is low because only $22 \%$ of beef cows are artificially inseminated (Miller, 2013). One option to better cover these districts would be to associate reproductive indicators with mortality as proposed by Perrin et al. (2010). 


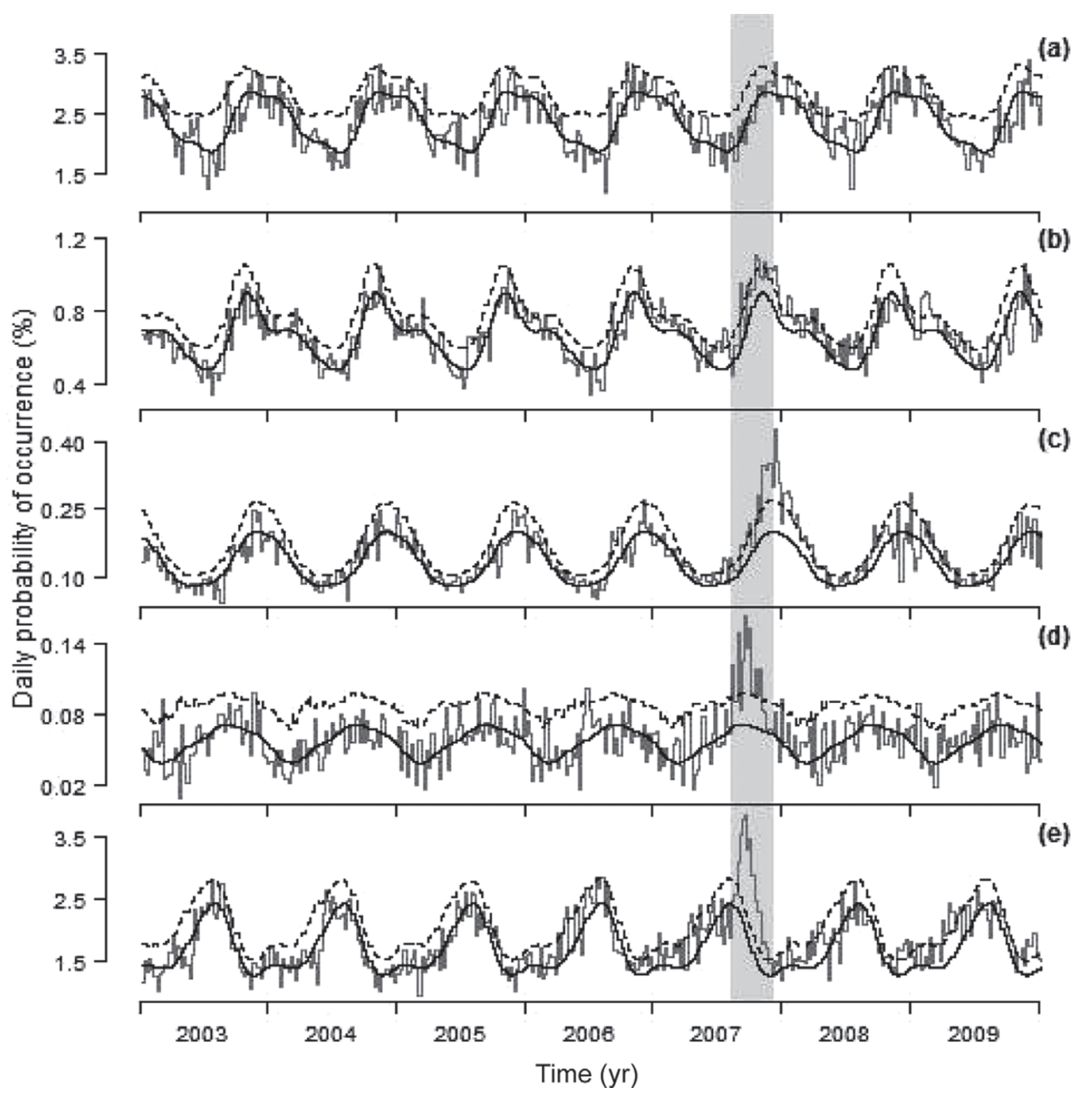

Figure 4. Observed (gray line), predicted baseline (black line), and predicted upper bound (black dashed line) of mean daily rate per week of occurrence of 5 indicators for the parous cow population in the French district Nord. From top to bottom, the indicators are 3-wk return to service (RTS; a), delayed RTS (b), very late RTS (c), premature calving (d), and short gestation (e). The gray area represents the bluetongue virus (BTV) epidemic period given by the first and last notification of veterinarians by clinical surveillance in the district. Time series were calculated on a weekly basis including animals with a parity $>0$ at AI and located in dairy herds enrolled in the official milk recording scheme.

The fact that reproductive indicators were related to complementary reproductive disorders increased the ability to detect the BTV epidemics in a district. Each indicator separately was more or less able to detect the BTV epidemic: the short gestation indicator had a large number of abnormal elevations, whereas the 3 -wk RTS indicator had a number close to zero. These results may be specific to the BTV-1 and BTV-8 epidemics, and other diseases will likely differently affect the set of indicators. Thus, the indicators should be kept together to be able to detect diseases with different effects on reproduction (types of disorders or disorder frequencies among the infected population). In addition, efforts to combine several data sources such as reproduction data, mortality, or milk produc- tion in a syndromic surveillance system might also be of interest.

\section{The Magnitude of BTV Effects on Reproductive Performance Indicators Determined the Ability to Detect the Epidemic}

The ability of a syndromic surveillance system to detect a disease is highly related to the magnitude of its effect on the indicators used (Reis and Mandl, 2003). In this study, the effect of the BTV epidemics (assessed by the total percentage error) varied between reproductive indicators and years, resulting in a variable ability to detect the BTV epidemic. Effects were particularly high for the indicators delayed RTS, very 


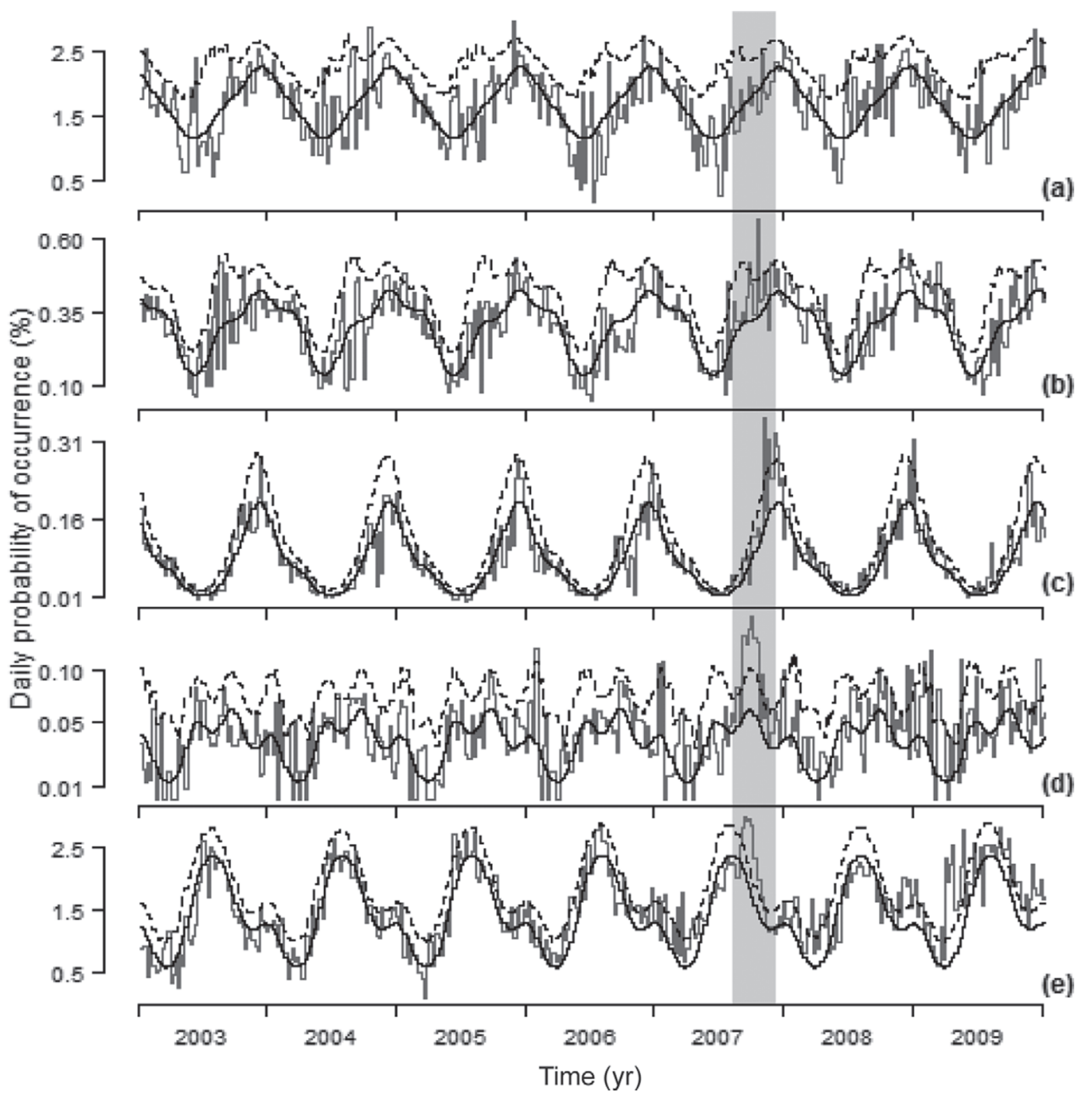

Figure 5. Observed (gray line), predicted baseline (black line), and predicted upper bound (black dashed line) of mean daily rate per week of occurrence of 5 indicators for the nulliparous heifers population in the French district Nord. From top to bottom the indicators are 3-wk return to service (RTS; a), delayed return to service (b), very late RTS (c), premature calving (d), and short gestation (e). The gray area represents the bluetongue virus (BTV) epidemic period given by the first and last notification of veterinarians by clinical surveillance in the district. Time series were calculated on a weekly basis including animals with a parity $=0$ at artificial insemination and located in dairy herds enrolled in the official milk recording scheme.

late RTS, premature calving, and short gestation. As a consequence, these indicators had the highest number of weeks with abnormal elevations. The detection of the BTV epidemic based on the very late RTS and premature calving indicators is in agreement with the increase of abortions observed in infected herds (Zanella et al., 2012; Nusinovici et al., 2012a). On the other hand, the effect of BTV was smallest on the delayed RTS indicator, although increase in RTS is a known effect of BTV (Santman-Berends et al., 2010; Nusinovici et al., 2012b). A new detectable effect of BTV was found with the short gestation indicator. The effect of BTV on this indicator was high, and abnormal elevations during the epidemic were the most frequent. The underlying biological mechanism is not known. The concomitance between the increase of short gestations and BTV notifications suggests that calving a few days earlier than expected is a consequence of an early health disorder after a BTV infection. It could result from a secondary effect of fever in infected cows triggering calving. Fever is the most frequent clinical sign of BTV and it occurs $1 \mathrm{~d}$ after the infection (Elbers et al., 2008; Dal Pozzo et al., 2009). However, no study showing this secondary effect has been found. Likely, calving a few days earlier than expected has no health consequences for the calf and these events are not reported. 


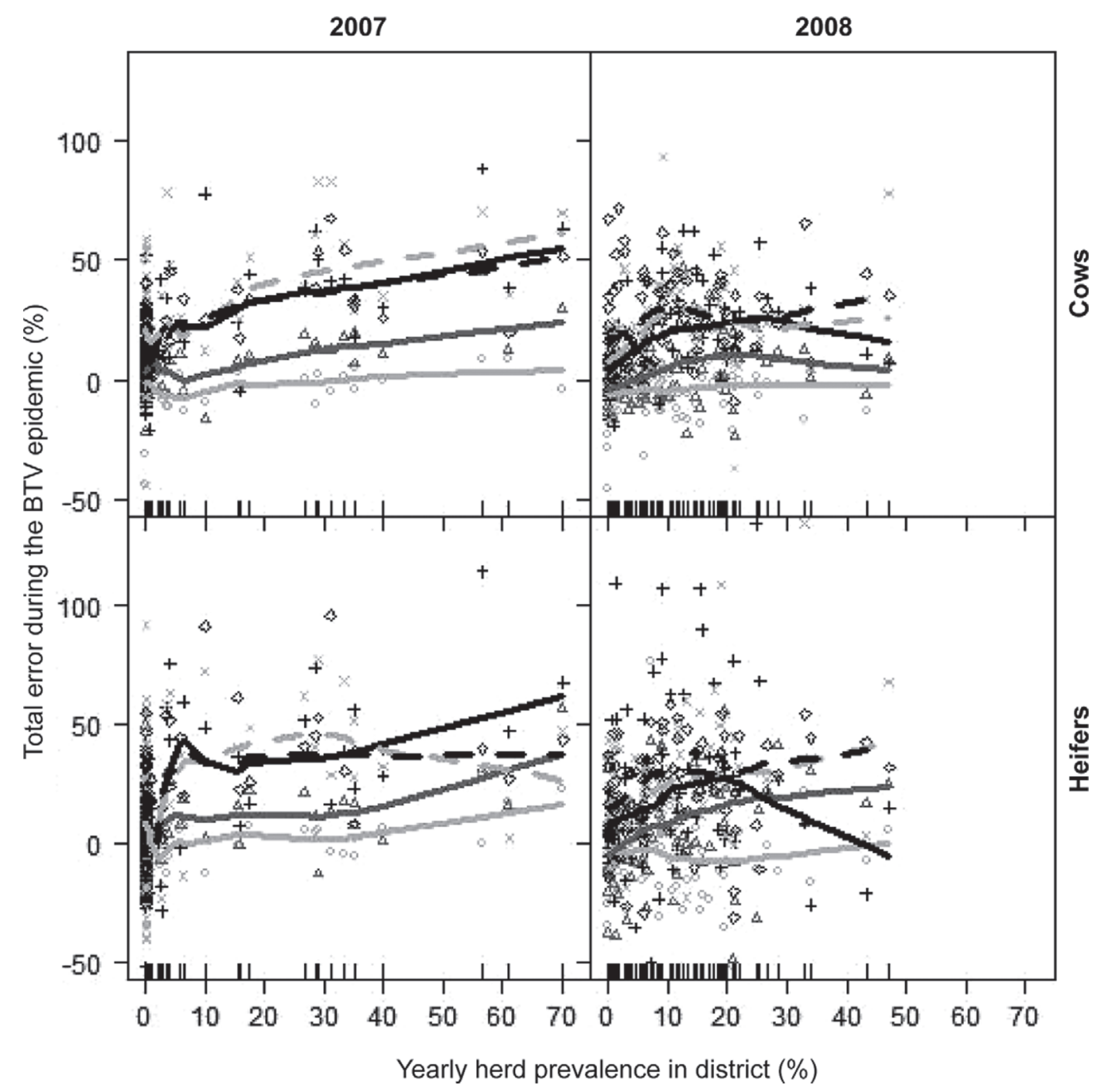

Figure 6. Total percentage error in indicator's time series during the bluetongue virus (BTV) epidemic as a function of between-herd prevalence in each of the 94 French districts. The total percentage error was calculated as the difference between expected and observed numbers of indicator events over the BTV epidemics period divided by the expected number of events. Results in each district (plots) and a smoothing function (lines) are calculated for 5 indicators: 3-wk return to service (RTS; circle, light gray line), delayed RTS (triangle, gray line), very late RTS (cross, black line), premature calving (inclined cross, light gray dashed line), and short gestation (square, black dashed line). The ticks on the $\mathrm{x}$-axis represent the yearly herd prevalence in each district.

From 2007 to 2008, the number of weeks with abnormal elevations decreased in BTV-infected districts. In 2007, the epidemic had a large effect because animals were naïve for BTV. In 2008, the proportion of naïve animals was lower because of immunity acquired in 2007 (in the northeastern districts infected in 2007) and as a result of the voluntary vaccination campaign implemented in France (started in spring 2008). The voluntary vaccination campaign resulted in $50 \%$ coverage of animals throughout France for BTV serotype 8 and between 80 and $90 \%$ of animals for serotype 1 (Mortureux, 2010).

\section{Random Fluctuations of Time Series Could Hide the Signal of the BTV Epidemic}

Despite the large impact of BTV, the number of weeks with abnormal elevations could be low because of high random fluctuations in time series, which cause a noise effect. Several authors reported that when the noise is high compared with the signal of the disease, the disease is not detectable (Reis et al., 2003). High noise is observed when the indicator rate is low as well as when the size of the at-risk population is small. 


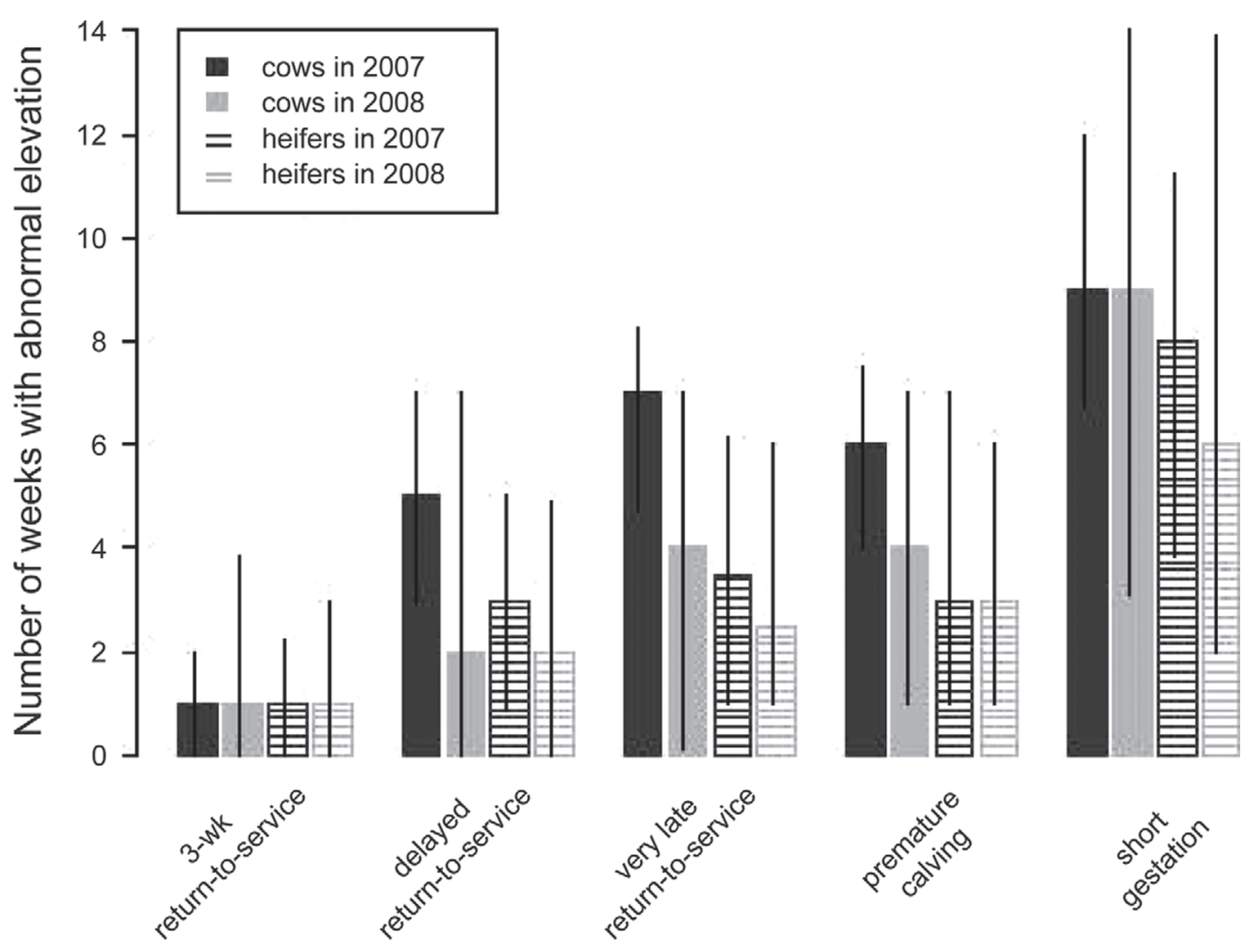

Figure 7. Number of weeks with abnormal elevations during the bluetongue virus (BTV) epidemic by indicator, year, and parity group. The bars show the median number and vertical lines show the percentiles 25 and 75 among all districts with herd prevalence $>5 \%$ and with a total number of herds >100 (16 districts in 2007 and 50 in 2008 out of 94 French districts).

Premature calving and very late RTS indicators were affected by BTV to a similar magnitude as short gestation but had fewer abnormal elevations due to a low baseline value of the indicator rate. High noise during the epidemic, related to the very low rate of occurrence of the event, hid elevations during the BTV outbreak, resulting in a lack of power to detect the outbreak. On the contrary, short gestation had a relatively high probability of occurrence and the associated time series were characterized by little noise in the time series.

Each indicator was affected by BTV to a similar magnitude in the heifer and cow populations but the heifer group had fewer abnormal elevations due to a smaller at-risk population. In our data, the number of heifers at risk was about half the number of cows at risk, leading to higher random fluctuations in time series. This was also observed in districts having similar herd prevalence of BTV but different cattle population sizes: the smaller the at-risk population in the district, the lower the number of abnormal elevations.

One option to improve the ability of detection could be to increase the at-risk population for individual indicators and thus reduce random fluctuations in time series. Grouping heifer and cow populations or enlarging the data set by including herds other than dairy herds enrolled in the official milk recording scheme could be of interest. Merging populations of several neighboring districts would also increase the at-risk population, but would result in an increase of the spatial unit of interest, which may hamper detection of disease that spreads from herd to herd at a low or moderate speed.

\section{Timeliness Varied Between Reproductive Indicators}

The reproductive indicators were elevated at different time points during the BTV epidemic according to their inherent characteristics. Indicators based on RTS after $26 \mathrm{~d}$ were late compared with indicators based on gestation length. Most likely, the long time interval between the interruption of gestation indicated by RTS after $26 \mathrm{~d}$ and re-insemination could be responsible for the late detection. This time interval includes the time needed to return to estrus after the interruption of gestation and the time for the farmer to detect return to estrus and to decide to re-inseminate. Thus, RTS is an event indicating an interruption of gestation that actually occurred several weeks before. Ryan et al. (1992) observed return-in-heat 5 to $16 \mathrm{~d}$ after abortions. It is 


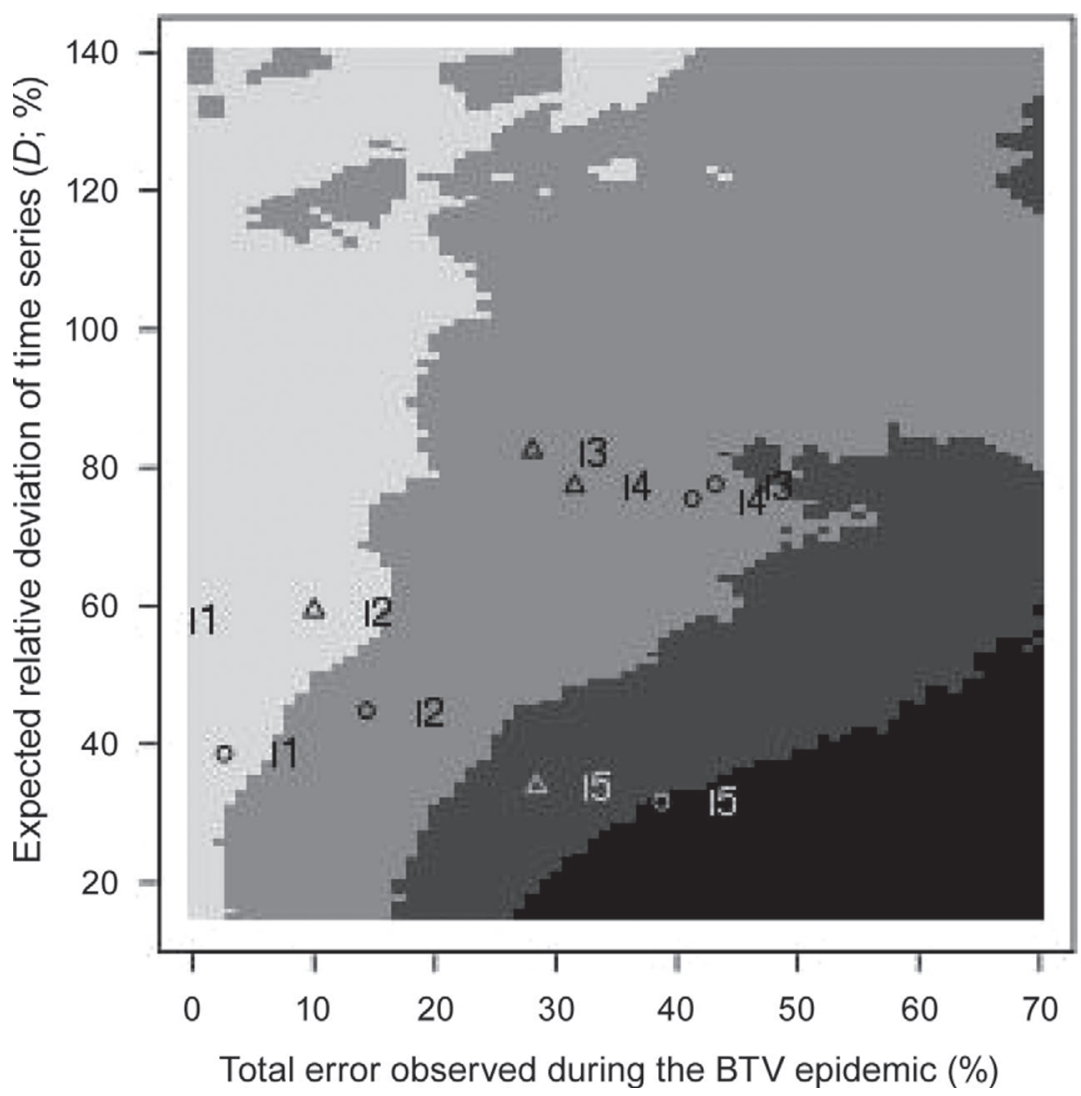

\section{Number of weeks with abnormal elevations}

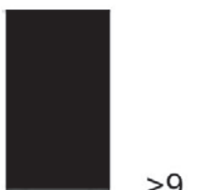

$>9$

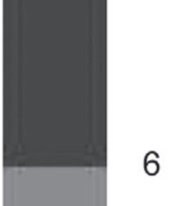

6

3

0

Figure 8. Number of weeks with abnormal elevations during the bluetongue virus (BTV) epidemic in 2007 and 2008 in each French district significantly infected by the epidemic (16 districts in 2007 and 50 in 2008 out of 94 French districts) and for each indicator's time series. These numbers were plotted as a function of the total percentage error observed during the BTV epidemic (effect of the epidemic on reproductive indicator) and the mean of the weekly upper confidence limit of time series during the BTV epidemic (given the random noise in time series). The expected upper confidence limit was expressed in relative deviation (in \%, notated $D$ in the text) to standardize its value among indicator's time series with different order of magnitude. A 2-dimensional smoothing function was applied using individual points to obtain a continuous graph. Moreover, for each indicator and year, the median characteristics of time series across all districts and parity groups are displayed (circles for year 2007 and triangles for year 2008): 3-wk return to service (RTS; I1), delayed RTS (I2), very late RTS (I3), premature calving (I4), and short gestation (I5).

expected that time interval between return-in-heat and the farmer detecting heat is long after $26 \mathrm{~d}$ post-AI because farmers do not watch the presumably pregnant cows so closely. Premature calving and short gestation are events more likely to occur soon after the acute phase of the BTV infection. Indicators based on gestation length are particularly interesting for early detection due to the absence of delay between the disease effect and the indicator of this effect.

First abnormal elevations of reproductive indicators were later than first notifications by veterinarians (clinical surveillance) with a shortest median delay of $20 \mathrm{~d}$ for the short gestation indicator in 2007. However, this delay may be lengthened by 2 particularities of this study. First, farmers and veterinarians were vigilant to a possible outbreak of BTV in France in 2007 because BTV-8 was detected the previous year in neighboring countries and was expected to spread again after the nonvector period. Therefore, disease awareness was high and the first notifications of clinical signs were probably made early in the epidemic, when relatively few animals were infected. In the case of an unexpected outbreak of an unknown disease, notification by veterinarians may be delayed, as happened during the Schmallenberg epidemics in 2011. The disease emerged at the end of the summer and the virus identified in November (Hoffmann et al., 2012; Doceul et al., 2013). This long delay can be explained by the fact that clinical symptoms during the acute phase of infection were not specific (fever, diarrhea, decrease in milk production) and that the virus was totally unknown before its emergence. In such cases, the timeliness of abnormal elevations of reproductive indicators could be better, given the median timeliness of $20 \mathrm{~d}$ observed in this study. Second, the implemented methods may have limitations. The district level and weekly basis used 

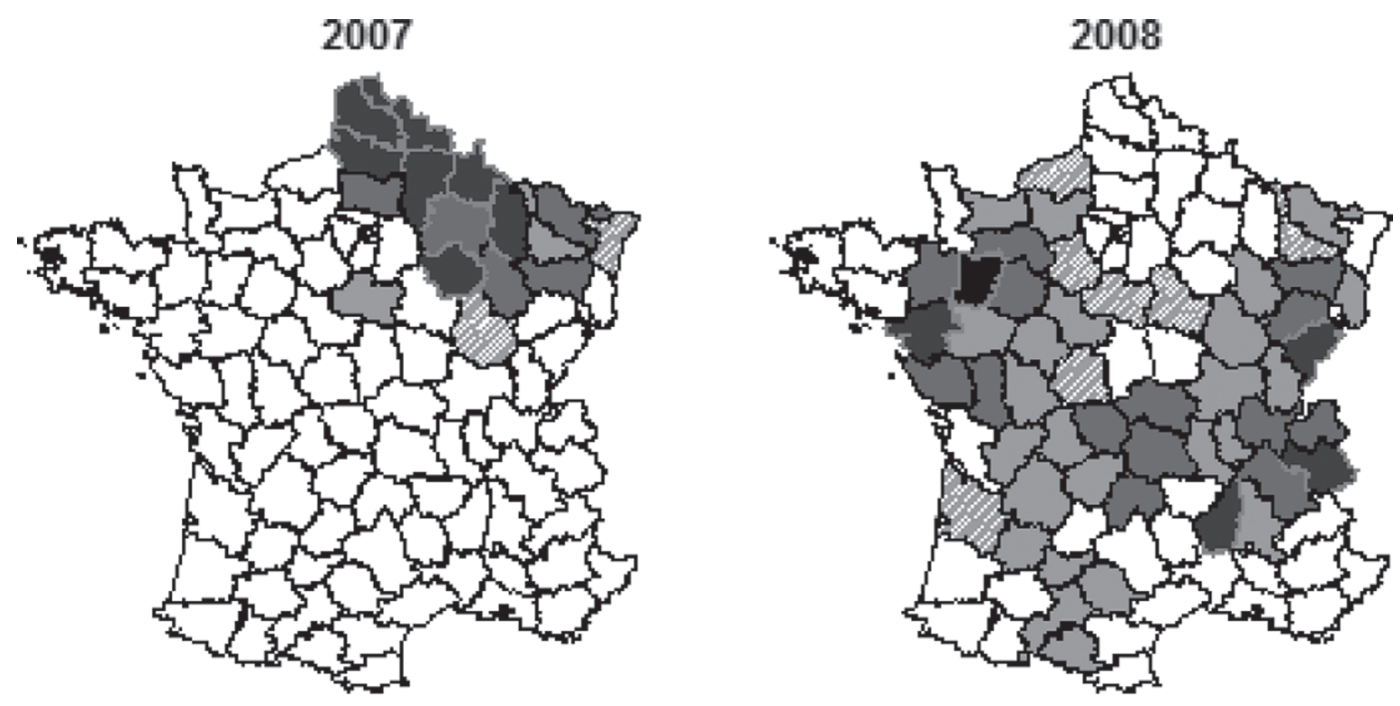

\section{Number of indicators}

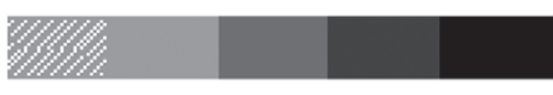

\section{$\begin{array}{lllll}0 & 1-2 & 3-4 & 5-6 & 7-8\end{array}$}

Figure 9. Number of indicators with abnormal elevations during at least 4 consecutive weeks during the bluetongue virus (BTV) epidemics for each of the 94 French districts. The maximal number is 10 , corresponding to 5 indicators calculated in 2 parity groups (cow and heifer populations). The virus had spread in northeastern France only in 2007 and expanded to most districts in 2008. Districts colored in white had herd prevalence $\leq 5 \%$ or number of exposed herds $\leq 100$.

may have been too large to detect the earliest cases of the BTV outbreak (Lombardo et al., 2003). Moreover, the upper bound of the $97.5 \%$ confidence interval, chosen to avoid a large number of false alarms, is effective in detecting deviations that reach a large magnitude but is not appropriate for detecting small elevations occurring in the early phase of the epidemics. Further development of statistical methods is needed to provide an acceptable compromise between early detection and reduced number of false alarms.

\section{Operational Constraints on Data Collection for Syndromic Surveillance Implementation}

In practice, reproduction events cannot be reported instantaneously and the delay between the reproduction event and the reporting must be added to the delay of detection quantified in this study. Artificial inseminations in dairy cattle are mostly performed by artificial inseminators (95.8\% of cases), who report AI with a mean delay of $4 \mathrm{~d}$ ( $8 \mathrm{~d}$ for $90 \%$ of AI; Institut de l'élevage, 2012). In future, this delay could increase because an increasing number of farmers perform AI on their own dairy cows $(+17 \%$ in 2012 and $+50 \%$ in 2011) and they send data with a longer delay than inseminators (mean delay $=45 \mathrm{~d} ; 124 \mathrm{~d}$ for $90 \%$ of $\mathrm{AI}$ ).
The regulation is less restrictive for farmers, who have to report the events within 1 mo compared with 2 wk for inseminators.

Implementation of the reproductive indicators in a real-time surveillance system requires adapting the statistical methods proposed here because only the earliest reported reproductive events can be used. Indeed, if the analysis begins when all reproduction events are reported, the delay of detection should increase dramatically. Consequently, rates of return to service and calving are underestimated and time series should have higher random fluctuations because of random delays in reporting. In this study, delays of reporting were unknown, and specific studies are required to adapt the statistical methods.

\section{CONCLUSIONS}

The set of 5 indicators of reproductive disorders measuring different biological phenomena and built from reproduction data can be used for syndromic surveillance in dairy cattle. This set of indicators was able to detect the emergence of the BTV epidemics in France despite a low demographic coverage on a weekly basis. However, the ability of the individual reproductive indicators to early detect the BTV epidemics was highly 


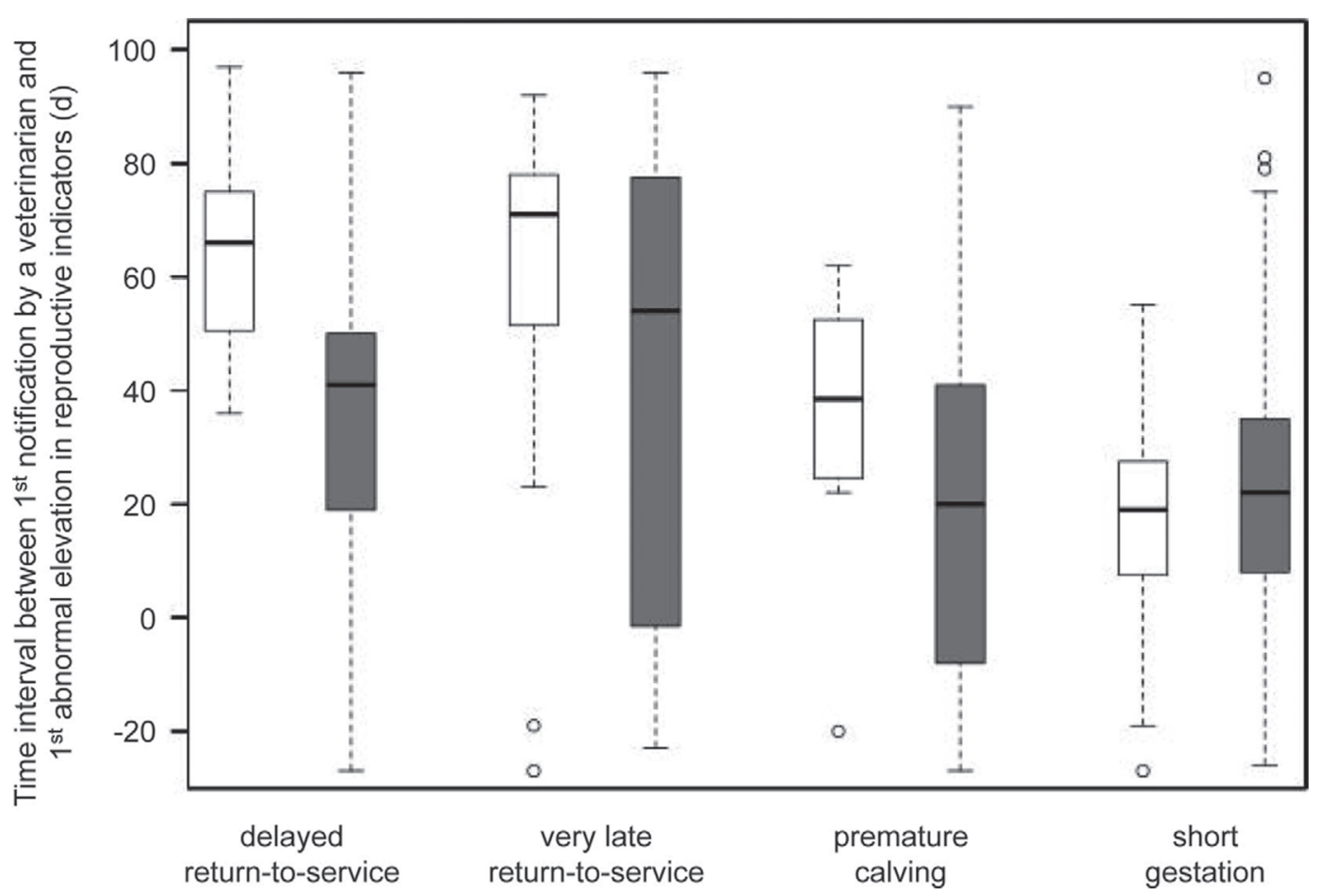

Figure 10. Boxplot of time intervals between the first notification of bluetongue virus (BTV) by a veterinarian and the first abnormal elevation due to the BTV epidemic in 2007 and 2008 in French districts. Eight boxplots are built corresponding to 2 years, 2007 (white) and 2008 (black), and 4 indicators: delayed return to service (RTS), very late RTS, premature calving, and short gestation. Boxplot is composed of a vertical box that includes $50 \%$ of the values, by a horizontal black line in the box that gives the median value, and by 2 dashed vertical lines that give the maximal and minimal values. The dashed vertical lines are limited to 3 times the standard deviation and values beyond this bound are represented by circles (outliers). Boxplot are built from time intervals calculated in districts with herd prevalence $>5 \%$ and a total number of herds $>100$ (16 in 2007 and 50 in 2008 out of 94 districts). The 2 parity groups are merged.

variable. An indicator based on the rate of calving after a short gestation length was the best able to detect the BTV epidemic at an early stage. It had a low number of false alarms in the absence of major epidemics (due to little random fluctuation) and it had high and frequent abnormal elevations during the BTV epidemic. This indicator was also the most timely for detection of BTV emergence. However, these results are specific to the BTV epidemics and would theoretically differ for other diseases with different effects on reproduction; it is thus recommended to monitor time series of the 5 reproductive indicators simultaneously. Finally, this study reveals the potential of reproductive data for syndromic surveillance, but further developments on statistical and computational methods are required to improve disease detection (timeliness, sensitivity, and specificity) and to account for operational constraints such as the time required for data gathering and analysis.

\section{ACKNOWLEDGMENTS}

This study was funded by Agence Nationale de la Recherche (Paris, France) in the framework of the Europe- an project EMIDA ERA-NET "Early Detection Data." Data were provided by CTIG (Centre de Traitement de l'Information Génétique, Jouy-en-Josas, France) and DGAL (Direction Générale de l'Alimentation, Paris, France).

\section{REFERENCES}

Basu, R. 2009. High ambient temperature and mortality: A review of epidemiologic studies from 2001 to 2008. Environ. Health 8:40.

Brouwer, H., C. J. M. Bartels, L. Van Wuijckhuise, and G. Van Schaik. 2012. Syndromic surveillance on blood samples of aborting cows for early detection of (emerging) infectious diseases using different statistical methods. Pages 233-244 in Proc. Annu. Conf. Soc. Vet. Epidemiol. Prev. Med., Glasgow, Scotland. Society for Veterinary Epidemiology and Preventive Medicine, UK.

Buckeridge, D. L. 2007. Outbreak detection through automated surveillance: A review of the determinants of detection. J. Biomed. Inform. 40:370-379.

Carpenter, T. E., M. Chrièl, and M. Greiner. 2007. An analysis of an early-warning system to reduce abortions in dairy cattle in Denmark incorporating both financial and epidemiologic aspects. Prev. Vet. Med. 78:1-11.

Choi, K., and S. B. Thacker. 1981. An evaluation of influenza mortality surveillance, 1962-1979. II. Percentage of pneumonia and influenza deaths as an indicator of influenza activity. Am. J. Epidemiol. 113:227-235.

Costagliola, D., A. Flahault, D. Galinec, P. Garnerin, J. Menares, and A. J. Valleron. 1991. A routine tool for detection and assessment 
of epidemics of influenza-like syndromes in France. Am. J. Public Health 81:97-99.

Dal Pozzo, F., K. De Clercq, H. Guyot, E. Vandemeulebroucke, P. Sarradin, F. Vandenbussche, E. Thiry, and C. Saegerman. 2009. Experimental reproduction of bluetongue virus serotype 8 clinical diseases in calves. Vet. Microbiol. 136:352-358.

Doceul, V., E. Lara, C. Sailleau, G. Belbis, J. Richardson, E. Bréard, C. Viarouge, M. Dominguez, P. Hendrikx, D. Calavas, A. Desprat, J. Languille, L. Comtet, P. Pourquier, J. F. Eléouët, B. Delmas, P. Marianneau, D. Vitour, and S. Zientara. 2013. Epidemiology, molecular virology and diagnostics of Schmallenberg virus, an emerging orthobunyavirus in Europe. Vet. Res. 44:31.

Elbers, A. R. W., A. Backx, E. Meroc, G. Gerbier, C. Staubach, G. Hendrickx, A. S. Spek, and K. Mintiens. 2008. Field observations during the bluetongue serotype 8 epidemic in 2006: I. Detection of first outbreaks and clinical signs in sheep and cattle in Belgium, France and the Netherlands. Prev. Vet. Med. 87:21-30.

Hateley, G. 2009. Bluetongue in northern Europe: The story so far. In Pract. 31:202-209.

Hoffmann, B., M. Scheuch, D. Hoper, R. Jungblut, M. Holsteg, H. Schirrmeier, M. Eschbaumer, K. V. Goller, K. Wernike, M. Fischer, A. Breithaupt, T. C. Mettenleiter, and M. Beer. 2012. Novel orthobunyavirus in cattle, Europe, 2012. Emerg. Infect. Dis. 18:469-472.

Institut de l'élevage. 2010. Chiffres-clés 2009. Chiffres-clés bovins issus de la BDNI 2009-04:1-20. Accessed July 1, 2014. http://idele. fr/recherche/publication/idelesolr/recommends/chiffres-cles-bdniannee-2009.html.

Institut de l'élevage. 2012. Coup d'oeil sur l'insémination par l'éleveur en 2012. Accessed May 15, 2014. http://idele.fr/domaines-techniques/ publication/idelesolr/recommends/coup-doeil-sur-linseminationpar-leleveur-en-2012.html.

Jones, K. E., N. G. Patel, M. A. Levy, A. Storeygard, D. Balk, J. L. Gittleman, and P. Daszak. 2008. Global trends in emerging infectious diseases. Nature 451:990-993.

Lombardo, J., H. Burkom, E. Elbert, S. Magruder, S. H. Lewis, W. Loschen, J. Sari, C. Sniegoski, R. Wojcik, and J. Pavlin. 2003. A systems overview of the Electronic Surveillance System for the Early Notification of Community-Based Epidemics (ESSENCE II). J. Urban Health 80:i32-i42.

Madouasse, A., A. Marceau, A. Lehébel, H. Brouwer-Middelesch, G. v. Schaik, Y. V. d. Stede, and C. Fourichon. 2014. Use of monthly collected milk yields for the detection of the emergence of the 2007 French BTV epizootic. Prev. Vet. Med. 113:484-491.

Mandl, K. D., J. M. Overhage, M. M. Wagner, W. B. Lober, P. Sebastiani, F. Mostashari, J. A. Pavlin, P. H. Gesteland, T. Treadwell, E. Koski, L. Hutwagner, D. L. Buckeridge, R. D. Aller, and S. Grannis. 2004. Implementing syndromic surveillance: A practical guide informed by the early experience. J. Am. Med. Inform. Assoc. $11: 141-150$.

Marcé, C., F. Beaudeau, N. Bareille, H. Seegers, and C. Fourichon. 2009. Higher non-return rate associated with Mycobacterium avium subspecies paratuberculosis infection at early stage in Holstein dairy cows. Theriogenology 71:807-816.

Miller, S. 2013. Flux des reproducteurs 2012 dans les races bovines allaitantes. Accessed May 15, 2014. http://idele.fr/?eID=cmis_
download\&oID=workspace://SpacesStore/ea8d6025-2342-4ab89cdd-5ef4537ed490.

Mintiens, K., E. Meroc, P. S. Mellor, C. Staubach, G. Gerbier, A. R. W. Elbers, G. Hendrickx, and K. De Clercq. 2008. Possible routes of introduction of bluetongue virus serotype 8 into the epicentre of the 2006 epidemic in north-western Europe. Prev. Vet. Med. $87: 131-144$.

Mortureux, M. 2010. Avis de l'Agence Française de Sécurité Sanitaire des Aliments relatif à la stratégie vaccinale contre la fièvre catarrhale ovine en France pour l'année 2010-2011. Afssa-Saisine no. 2010-SA-0140. Agence Française pour la Sécurité Sanitaire des Aliments, Maisons-Alfort, France.

Nusinovici, S., H. Seegers, A. Joly, F. Beaudeau, and C. Fourichon. 2012a. Increase in the occurrence of abortions associated with exposure to the bluetongue virus serotype 8 in naïve dairy herds. Theriogenology 78:1140-1151.

Nusinovici, S., H. Seegers, A. Joly, F. Beaudeau, and C. Fourichon 2012b. Quantification and at-risk period of decreased fertility associated with exposure to Bluetongue virus serotype 8 in naïve dairy herds. J. Dairy Sci. 95:3008-3020.

Perrin, J.-B., C. Ducrot, J.-L. Vinard, E. Morignat, A. Gauffier, D. Calavas, and P. Hendrikx. 2010. Using the National Cattle Register to estimate the excess mortality during an epidemic: Application to an outbreak of Bluetongue serotype 8 . Epidemics $2: 207-214$.

Purse, B. V., H. E. Brown, L. Harrup, P. P. C. Mertens, and D. J. Rogers. 2008. Invasion of bluetongue and other orbivirus infections into Europe: The role of biological and climatic processes. Rev. Sci. Tech. 27:427-442.

R Core Team. 2012. R: A Language and Environment for Statistical Computing. R Foundation for Statistical Computing, Vienna, Austria.

Reis, B. Y., and K. Mandl. 2003. Time series modeling for syndromic surveillance. BMC Med. Inform. Decis. Mak. 3:2.

Reis, B. Y., M. Pagano, and K. D. Mandl. 2003. Using temporal context to improve biosurveillance. Proc. Natl. Acad. Sci. USA 100:1961-1965.

Ryan, D. P., H. F. Rodriguez, D. L. Thompson, A. M. Saxton, and R. A. Godke. 1992. Luteal maintenance in cattle after conceptus death during the 1st trimester of gestation. J. Anim. Sci. $70: 836-840$

Santman-Berends, I. M., J. J. Hage, P. A. van Rijn, J. A. Stegeman, and G. van Schaik. 2010. Bluetongue virus serotype 8 (BTV-8) infection reduces fertility of Dutch dairy cattle and is vertically transmitted to offspring. Theriogenology 74:1377-1384.

Shmueli, G., and H. Burkom. 2010. Statistical challenges facing early outbreak detection in biosurveillance. Technometrics 52:39-51.

Wilson, A. J., and P. S. Mellor. 2009. Bluetongue in Europe: Past, present and future. Philos. Trans. R. Soc. B Biol. Sci. 364:26692681.

Zanella, G., B. Durand, E. Sellal, E. Breard, C. Sailleau, S. Zientara, C. A. Batten, P. Mathevet, and C. Audeval. 2012. Bluetongue virus serotype 8: Abortion and transplacental transmission in cattle in the Burgundy region, France, 2008-2009. Theriogenology $77: 65-72$. 